\title{
Usage of QR Codes in Promotion on Social Networks
}

\author{
Zlatko Čović \\ Subotica Tech - College of Applied Sciences, \\ Department of Informatics \\ Subotica, Serbia \\ chole@vts.su.ac.rs
}

\author{
Janoš Šimon \\ Subotica Tech - College of Applied Sciences \\ Department of Informatics \\ Subotica, Serbia \\ simon@svts.su.ac.rs
}

\begin{abstract}
This paper presents web based project that was developed for the purpose of promotion of company or brand on social networks with the use of $Q R$ codes. System contains detection script which collects data from scanned QR codes Paper brings information of the realized project; it also gives results of testing.
\end{abstract}

Keywords - mobile devices; promotion; social networks; web; QR code

\section{INTRODUCTION}

The trend in the marketing companies is the use of $\mathrm{QR}$ codes. They are found on magazine pages, billboards, product boxes, beverages, advertisement papers, flyers, and other marketing mediums. A qualitative focus group study conducted in Japan found that loyal customers would use QR codes in order to access promotional information and discounted items [1]. The new platforms that QR codes can be used are social networks. People are connected and they post and share large amount of information. Some of social networks have options where page owner can set the targeting population for his promotion [8].

In [9] Sago (2011) concluded that ads with the integrated QR codes allows consumer to have many benefits. Consumer can visit web sites that provide additional information, they can download coupons, enter sweepstakes, connect to a company's social media web sites, and they can access information while shopping.

Based on results of research (Teuta, Payal and Toru 2013) it can be said that unsuited implementation, poor execution, and lack of enough awareness among the consumers can be a big barrier that can stop the progress of usage QR codes in mobile marketing on different platforms.

One of the results of case study (Shing, Jung and Chang 2012) shows that user intentions and behaviors are largely influenced by the perception of the quality of QR codes. The results of their model show that interactivity is a key behavioral antecedent to the use of $\mathrm{QR}$ codes.

In cooperation with one ICT company from Subotica, little research was done to determine how users react on various representation of QR code. Our goal was to see to how users react to the various types of $\mathrm{QR}$ codes.

The Second chapter gives some information about QR codes. The third chapter describes the implementation of the system showing used QR codes. Schema and security of system are also presented [6] [7]. More technical details can be found in part that describes the process of detection of mobile devices and the generation of promo codes.

In the fourth chapter the experimental results are presented.

\section{WHAT IS QR CODE}

QR code (abbreviated from Quick Response Code) is a type of matrix barcode (or two-dimensional barcode) first designed for the automotive industry in Japan in 1994 by Denso Wave company. This code is a machine-readable optical label that contains information about the item to which it is attached. A QR code uses four standardized encoding modes (numeric, alphanumeric, byte/binary, and kanji) to efficiently store data; extensions may also be used [2]. This code can store 7,089 characters, compared to traditional bar code that can hold at most 20 digits, and it gives great range of opportunities for implementation. These codes found their usage in the field of marketing and promotion because their ease of implementation.

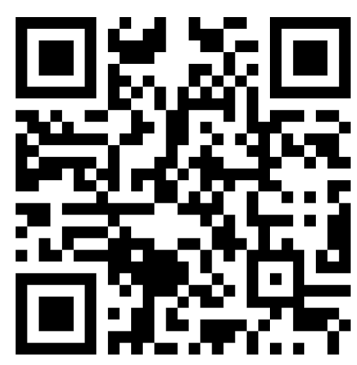

Fig. 1. Example of QR code

With the big penetration and development of mobile devices, QR code has found its place in the field of marketing, promoting, commercial tracking, entertainment, transport ticketing and for giving people large variety of information that can be used with different types of applications. Every owner of mobile device with appropriate scanning software (QR code reader or scanner) can easily scan $\mathrm{QR}$ code throw mobile device's camera [3].

\section{A. Content of $Q R$ code}

QR code can store different types of data: 
- URL/web address, the most used type of QR codes. Code represents web address that can be easily opened by the web browser on mobile device

- Text, to store textual data

- Send email, after scanning the code, user gets opportunity to send email to predefined address with predefined or custom message.

- Send SMS, after scanning the code, user gets opportunity to send SMS to predefined phone number with predefined or custom message

- Geolocation, code contains data for latitude and longitude. This data can be used with application that uses some kind of maps.

- Calendar, code contains data of some event or happening. This data can be stored in calendar option of mobile device.

- WIFI network, code contains access parameters for WIFI network.

- vCard, code contains contact information of person that can be stored in contacts of mobile device [3].

One of the most popular ways of using QR codes is directing users to a specific website [4]. This is an ideal opportunity for web marketing, promotion and e-commerce. After scanning the code, user will be redirected to web site with the products or information that company offers. Companies can collect data of mobile devices that can be used in measuring effectiveness of campaign.

\section{IMPLEMENTATION OF SYSTEM}

Generation and usage of QR codes is easy. Anybody can generate own QR code with free generators or with free libraries for programming languages. The bigger challenge is how to present QR code, is it good to show pure code, or to mix it with provocative-interesting text or some graphic. This text and graphic can be associated with the brand or product to force fans to scan it. Also some short video material could contain $\mathrm{QR}$ code.

In our research 5 types of QR code were used to promote sale of products. Four types were images and the $5^{\text {th }}$ was video file. These codes were posted to the company page on Facebook in the interval of two days. QR codes contain the same web address, only difference is in the parameter $q r$ that indicates the type of QR code.

System used in this research is multiplatform web based application with two levels of access: user and administrator. User can scan the code, while administrator has access to detail statistics. In the development of application following technologies and programming languages were used: HTML5, JavaScript, CSS3, PHP, MySQL and BootStrap framework. Emphasis was given to the security of the system.

\section{A. Used $Q R$ codes}

As it was mentioned in previous, $4 \mathrm{QR}$ codes were images. Pure QR code without any additional text or graphic was first posted. Second was QR code with the logo of company.

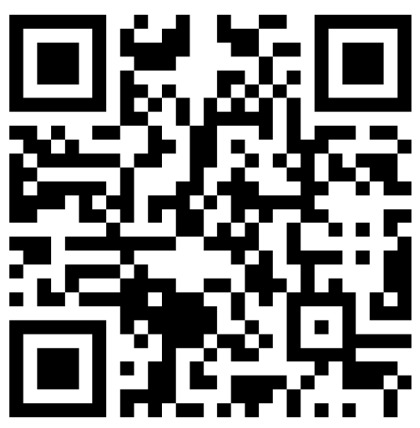

Fig. 2. Pure QR code without any additional content
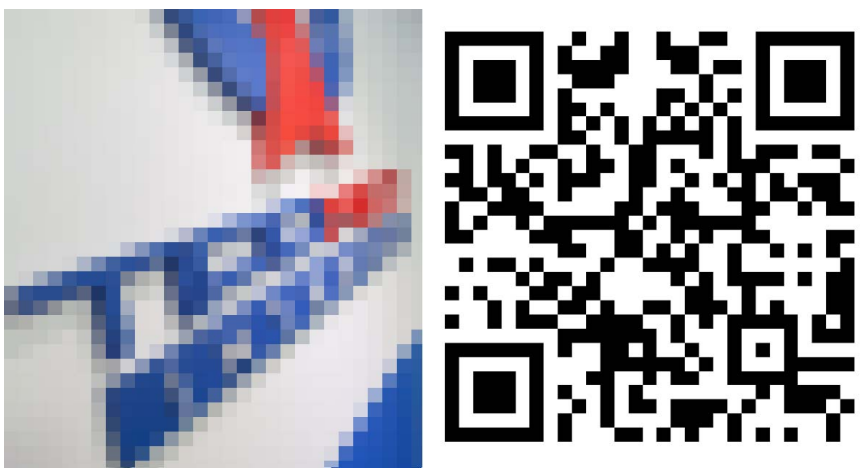

Fig. 3. QR code with the combination of company logo

After two days another two QR codes were posted. First was QR code with slogan of campaign and second was code with company logo and slogan of campaign.

Third day short video material has been posted. This material contained text and images of company and campaign. In the end of video material QR code was shown.

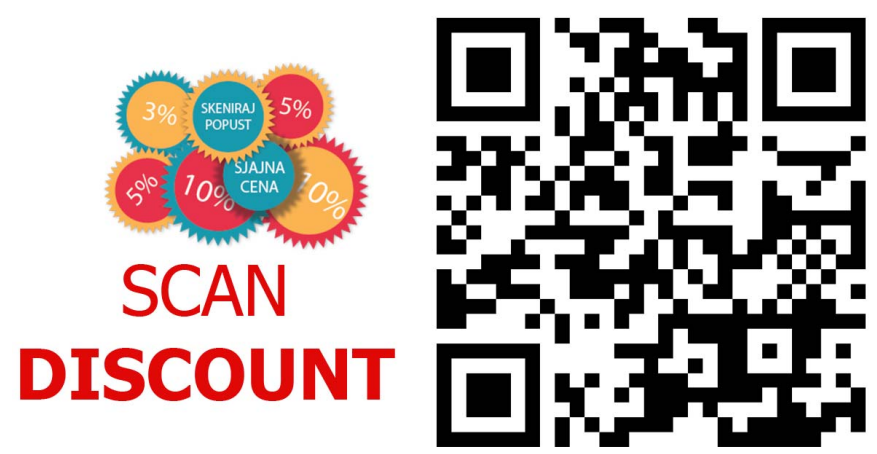

Fig. 4. QR code with slogan of campaign 


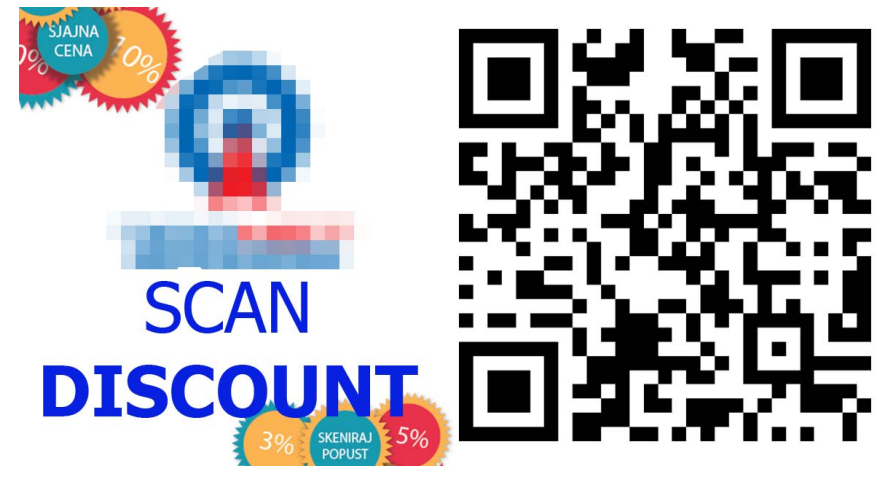

Fig. 5. QR code with the slogan of campaign and the company logo

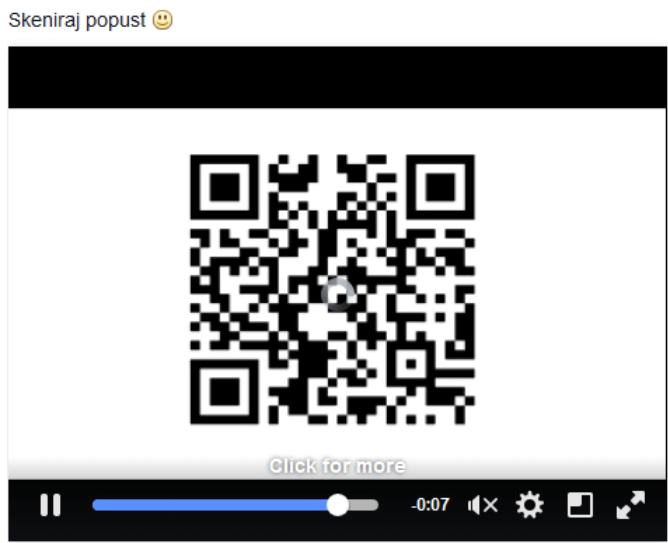

Fig. 6. Video material with $\mathrm{QR}$ code in the end

\section{B. Schema of system}

Fig 7. presents the schema of a system. System is divided at two parts, one on College's web server and second on company's web server. Detection script and database are on College server. Script that receives user response with promo code is located on company web server.

\section{How system works}

User sees post on Facebook page of company and scans the QR code with his mobile device. Mobile device shows decoded text - URL that can be visited throw web browser on mobile device. Every QR code contains the same URL with different parameter: http://qrcode.vts.su.ac.rs/index.php?qr=number. Number is parameter that represents primary key (id) of QR code in database. Script detects access device, and if it is mobile phone or tablet script checks if Cookie exists and generates random promo code if it is needed. Promo code is string of small and big characters. If Cookie is set, script doesn't generate promo code. Duration of Cookie is 5 minutes.

After generating promo code and storing data, user is redirected to the company's web page that shows more information of campaign and also the generated promo code. With this promo code, user can by article with a discount of 3 , 5 or 10 percent. Every promo code can be used just once. During the redirection, script sends a generated promo code and hash of this promo code. Promo code is not stored on company's server.

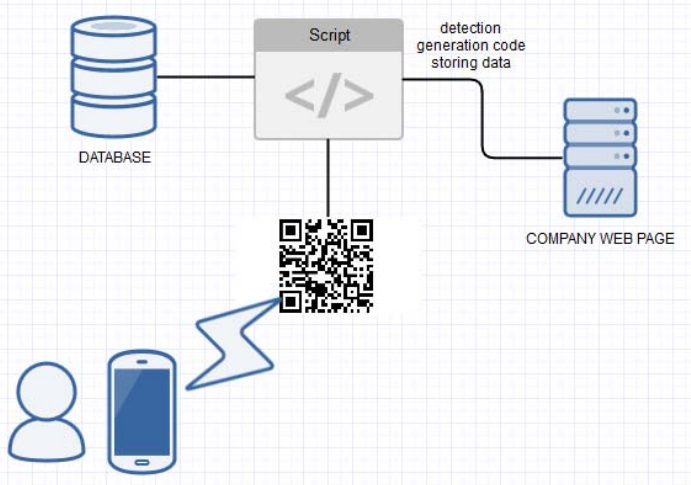

Fig. 7. Schema of the system

If user's device is not recognized as mobile, user gets message that this QR code should be scanned only with mobile device. It is very important because on web exists several online tools that can scan QR code. This scans are not relevant for this experiment and they should be ignored.

Detection script collects information of IP address, Useragent string, time of scanning and type of QR code. These data are stored in database.

\section{Detection script}

Detection of access device is very important because only users with mobile devices (mobile phone and tablet) are allowed to get promo code. Main part of detection script is Mobile Detect lightweight PHP class. It uses User-Agent string combined with specific HTTP headers to detect the mobile environment [5].

Below the part of the detection code is shown. It is enough to include Mobile Detect.php file and to make a new object of Mobile_Detect class. After that we can make some checks of GET parameters and call methods of object to determine if access device is mobile device.

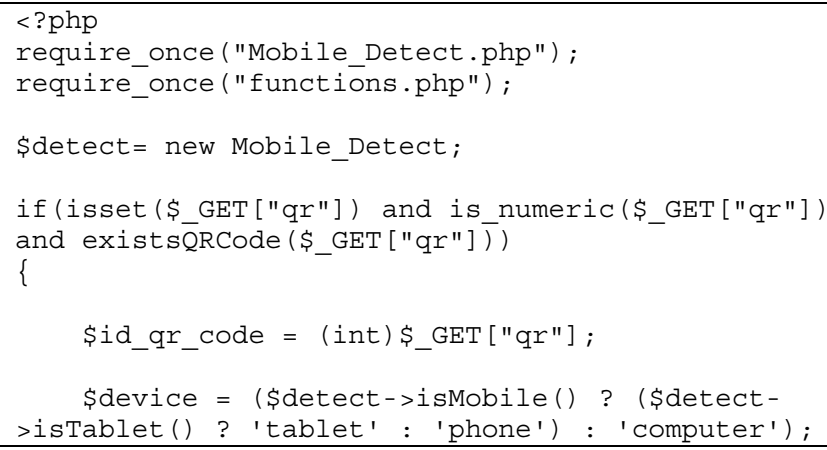

\section{E. Security techniques and methods}

Security is very important in every system. Administrative interface is protected with .htaccess file. It requires valid username and password.

Detection script allows access only to users of mobile devices. Script also checks Cookie data to prevent generating another promo code with simple refresh of web page. 
When the user is redirected to the company's web page, script on that page handles the GET parameters sent together with request. There are two GET parameters, promo code as plain text and coded hash of that promo code. For better security reasons, promo code uses additional SALT string. This technique puts random string (SALT) to the beginning and to the end of promo code. Resulting string is encrypted with MD5 cryptographic hash function. Script on company's web page checks that promo code matches the encrypted hash. If is not the case, user gets adequate message.

\section{F. Administrative interface}

Administrator can access all data through administrative interface. He can

- See the number of scanning for every QR code

- $\quad$ see detail statistics of every scanning

- $\quad$ change the status of stored promo codes

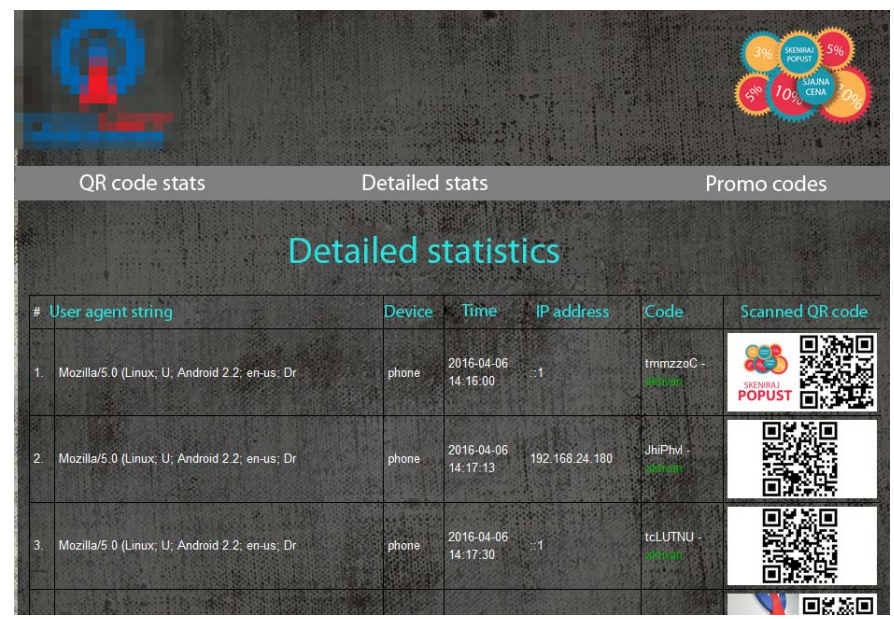

Fig. 8. Administrative interface

\section{EXPERIMENTAL RESULTS}

Experiment has lasted 10 days. Fig. 9 shows the number of scanning.

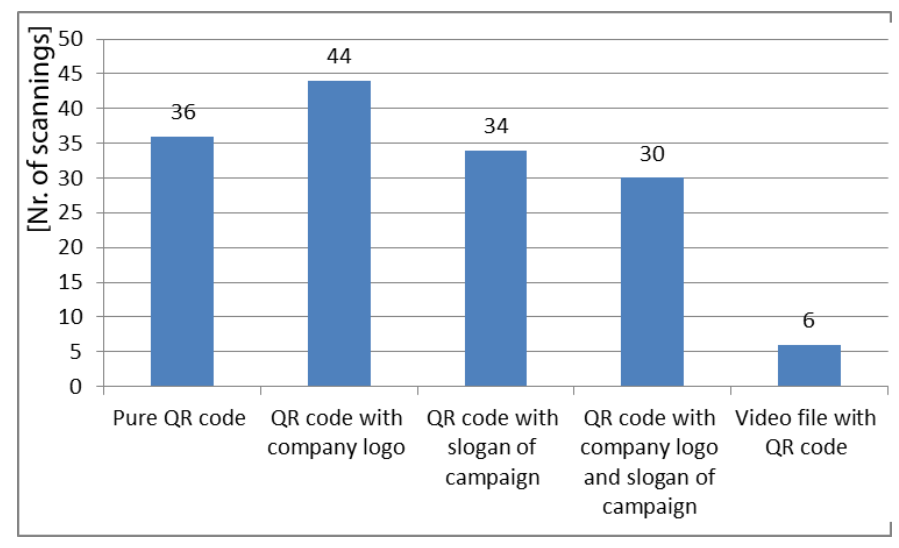

Fig. 9. Total scan number for every QR code
Of the total number of scanning only $2 \%$ of users scanned QR codes with tablet, all other scans were done with mobile phone. Based on results it can be concluded that two QR codes that were posted first on Facebook page have the largest number of scanning. Users have trust in company, they like posts with company logo. Usage of pure QR code without additional material encourages people to scan it. People are curios and they want to see what is behind encrypted data.

The smallest number of scanning belongs to the video material. The reasons for very small number can be that the video material was posted last or it was not so interesting for the fans of company's page.

For getting more relevant data, the next experiment should be done. That new research will post the $\mathrm{QR}$ codes in reverse order. Also it is better to start sale campaign before upcoming holidays, when people usually buy more presents.

\section{CONCLUSIONS}

This paper presents web based project that which was developed for the purpose of promotion of company or brand on social networks with the use of QR codes. System contains detection script which collects data from scanned QR codes.

In the development of application following technologies and programming languages were used: HTML5, JavaScript, CSS3, PHP, MySQL and BootStrap framework. Emphasis was given to the security of the system.

The big challenge is how to present QR code, is it good to show pure code, or to mix it with provocative-interesting text or some graphic. In this research five types of QR codes were used, four as graphic images and one as video material that contains QR code. After scanning the QR code user is redirected to company's page that shows promo code and information about discount campaign.

Based on results it can be said that two QR codes that were first posted to the Facebook company page have the largest number of scanning.

To ensure the efficiency of the use of this system, it would be advisable to implement it in promotions of companies or brands in other fields. We would implement smart approach in detection of mobile devices using Tera-Wurfl project, which implements Levenshtein Distance algorithm in detection process.

\section{REFERENCES}

[1] S. Okazaki, A. Navarro, and S. Campo, "Cross-Media Integration of QR Code: A Preliminary Exploration", Journal of Electronic Commerce Research, Vol.14 No.2, pp. 137-148, 2013.

[2] QR Code [Online]. Available: http://www.qrcode.com/en/qrfeature.html [Last accessed: July 2016].

[3] K. Kanalaš, Z. Čović, I. Marović, D. Buljovčić, "Implementacija QR koda u cilju promocije na društvenim mrežama", Proceedings of the International conference on E-trgovina 2016, Palic, Serbia, 20-22. 04. 2016 
[4] S. Palfi, B. Tot, Z. Čović, "Upotreba QR kodova u elektronskom poslovanju", Proceedings of the International conference on E-trgovina 2013, Palic, Serbia, 24-26. 04. 2013.

[5] Mobile Detect [Online]. Available: http://mobiledetect.net/ [Last accessed: July 2016].

[6] J. Simon, Z. Čović, "Data Management of the Automomous Mobile Devices and Internet of Things", Annals of Faculty Engineering Hunedoara - International Journal of Engineering, Vol. 13, No. 3, pp. 265-268, 2015.

[7] J. Simon, "Concepts of the Internet of Things from the Aspect of the Autonomous Mobile Robots", Interdisciplinary Description of Complex Systems Vol.13 No.1, pp. 34-40, 2015.

[8] J. Simon, Z. Čović, I. Fürstner, L. Gogolak, D. Dobrilović, "The Web of Things and Database Services", Proceedings of the International conference on Applied Internet and Information Technologies AIIT 2015, pp. 235-238, Zrenjanin, Serbia, 2015.

[9] B. Sago, "The Usage Level and Effectiveness of Quick Response (QR) Codes for Integrated Marketing Communication Purposes among College Students", International Journal of Integrated Marketing Communications, Fall, 7-17.,2011.

[10] T. Cata, Payal S. Patel and T. Sakaguchi, "QR Code: A New Opportunity for Effective Mobile Marketing", Journal of Mobile Technologies, Knowledge and Society, Vol. 2013, Article ID 748267, DOI: 10.5171/2013. 748267., pp. 1-7, 2013.

[11] D. Shin, J. Jung, B. Chang, "The psychology behind QR codes: User experience perspective", Journal of Computers in Human Behavior, Vol. 28, No. 4, pp 1417-1426, 2012. 